\title{
The Defect of Ku70 Affects Sensitivity to X-Ray and Radiation-Induced Caspase- Dependent Apoptosis in Lung Cells
}

\author{
Manabu KOIKE ${ }^{1) *}$, Yasutomo YUTOKU ${ }^{1,2)}$ and Aki KOIKE ${ }^{1)}$ \\ ${ }^{1)}$ DNA Repair Gene Res., National Institute of Radiological Sciences, 4-9-1 Anagawa, Inage-ku, Chiba 263-8555, Japan \\ ${ }^{2)}$ Graduate School of Science, Chiba University, Chiba 263-8522, Japan
}

(Received 25 July 2012/Accepted 31 October 2012/Published online in J-STAGE 14 November 2012)

ABSTRACT. The DNA repair protein Ku70 is a key player in chemoresistance to anticancer agents (e.g., etoposide) or radioresistance. The responses of different organs to radiation vary widely and likely depend on the cell population in the organs. Previously, we established and characterized Ku70-deficient murine lung epithelial (Ku70 -/- MLE) cells and found that these cells are more sensitive than Ku70 +/MLE cells (control cells) to X-irradiation, as determined by clonogenic survival assay; however, the mechanism underlying this sensitivity remains unclear. In this study, we examined the mechanism by which X-irradiation triggers the death of Ku70 -/- MLE cells. Our results showed that Ku70 -/- MLE cells were more sensitive to radiation-induced apoptosis than control cells, although X-irradiation activated caspase-3 and caspase-7, and cleaved PARP in both cell lines. We also examined the expression level of phosphorylated $\mathrm{H} 2 \mathrm{AX}(\gamma \mathrm{H} 2 \mathrm{AX})$, which is a marker of DSB, and observed the phosphorylation of $\mathrm{H} 2 \mathrm{AX}$ and the elimination of $\gamma \mathrm{H} 2 \mathrm{AX}$ in both cell lines after X-irradiation. The elimination in Ku70 -/- MLE cells was slower than that in control cells, suggesting that DSB repair activity in the Ku70 -/- MLE cells is lower than that in control cells. These findings suggest that Ku70 might play a key role in the inhibition of apoptosis through the DSB repair pathway in lung epithelial cells. Our findings also suggest that these cell lines might be useful for the study of Ku70 functions and the Ku70-dependent DSB repair pathway in lung epithelial cells.

KEY WORDS: anticancer treatment, epithelial cell, $\gamma \mathrm{H} 2 \mathrm{AX}, \mathrm{Ku} 70, \mathrm{Ku} 80$.

doi: 10.1292/jvms.12-0333; J. Vet. Med. Sci. 75(4): 415-420, 2013

Chemotherapy and radiotherapy are well-established treatments for cancer. Various chemotherapeutic drugs, e.g., etoposide and bleomycin, and ionizing radiation have been clinically applied to the treatment of many types of animal and human malignancies. On the other hand, the responses of different organs to clinical chemotherapeutic drugs or radiation vary widely and likely depend on the intrinsic chemosensitivity or radiosensitivity of different cell populations in the organs. Thus, it is important to understand the mechanisms underlying the chemoresistance or radioresistance of each normal tissue type and each cancer cell type.

A DNA double-strand break (DSB) is the most critical DNA damage [5]. Unrepaired or improperly repaired DSBs can lead to chromosomal truncations and translocations, which can contribute to the development of cancer in higher eukaryotic organisms. In addition, one DSB is sufficient to kill a cell, when it is not repaired. DSBs are induced following exposure to ionizing radiation as well as treatment with etoposide or bleomycin [16, 23, 28]. The nonhomologous DNA-end-joining (NHEJ) repair process, which repairs a major fraction of DSBs in somatic cells of all multicellular eukaryotes including humans, is considered to begin with the binding of $\mathrm{Ku}$, i.e., a heterodimer of $\mathrm{Ku} 70$ and $\mathrm{Ku} 80$ [4, $5,20,25]$. On the other hand, at nascent DSB sites, histone

*Correspondence to: Koike, M., DNA Repair Gene Res., National Institute of Radiological Sciences, 4-9-1 Anagawa, Inage-ku, Chiba 263-8555, Japan.

e-mail: m_koike@nirs.go.jp

(C)2013 The Japanese Society of Veterinary Science
$\mathrm{H} 2 \mathrm{AX}$ molecules near these sites are rapidly phosphorylated at serine $139(\gamma \mathrm{H} 2 \mathrm{AX})$ [24]. The detection of $\gamma \mathrm{H} 2 \mathrm{AX}$ using a specific antibody is the most sensitive method currently available for identifying DSBs.

Many of the studies of the radiosensitivity of cells have been performed using cultured cells or mice exposed to ionizing radiation. It is likely that $\mathrm{X}$-irradiation activates cell death pathways such as apoptosis and autophagy in a tissue- or cell-type-specific manner [2, 18]. Lung cancer is classified into non-small cell lung cancer (NSCLC), which includes adenocarcinoma and squamous cell carcinoma (SCC), and small cell lung cancer (SCLC). It has been reported that BRCA1, BRCA2 and Ku80 are tumor suppressors in lung adenocarcinoma and SCC [19]. Recently, Tseng et al. (2009) have demonstrated a significant association between the polymorphisms of genes in the NHEJ pathway and lung cancer susceptibility and prognosis [27]. Although suppression of $\mathrm{Ku} 70$ using the antisense nucleic acid strategy increases radiosensitivity and chemosensitivity in a human lung carcinoma cell line, the mechanisms underlying these sensitivities have not been clarified [21].

The DNA repair protein $\mathrm{Ku} 70$ is a key factor for chemoresistance to anticancer agents (e.g., etoposide) or radioresistance. Therefore, it is important to clarify the role of $\mathrm{Ku} 70$ in each of the cell and tissue types. Ku70-deficient embryonic stem cells and bone marrow cells from Ku70 knockout mice $(\mathrm{Ku} 70-/-)$ show an increased sensitivity to ionizing radiation $[3,22]$. However, there are few reports about the epithelial cells from $\mathrm{Ku} 70-/-$ mice, although more than $90 \%$ of cancers are of epithelial cell origin. Recently, we have established and characterized Ku70-deficient murine 
lung epithelial (MLE) cell lines (Ku70 -/- MLE cells) [12]. These cells showed an increased sensitivity to X-irradiation compared with Ku70 +/- MLE cells. In this study, we examined the mechanism by which X-irradiation triggers the death of Ku70 -/- MLE cells. Our findings suggest that the sensitivity to X-irradiation-induced apoptosis increased by the $\mathrm{Ku} 70$ deficiency is associated with the accumulation of DSBs in MLE cells.

\section{MATERIALS AND METHODS}

Cell lines and cultures: Ku70-deficient murine lung epithelial (MLE) cell lines established from $\mathrm{Ku} 70-/-$ mice and control mice $(\mathrm{Ku} 70+/-)$ were cultured as described in previous studies $[11,12]$.

$X$-irradiation: Cells were exposed to X-rays at room temperature, as described previously [7]. X-rays were generated at $200 \mathrm{kVp} / 20 \mathrm{~mA}$ and filtered through $0.5-\mathrm{mm} \mathrm{Cu}$ and $\mathrm{Al}$ filters, as described previously [7].

Western blot analysis: Western blot analysis was performed as previously described $[9,12,13,16]$. The supernatants were electrophoresed on 5-20\% SDS-polyacrylamide gels (Wako, Osaka, Japan). The fractionated products were electrotransferred onto Hybond-P membranes (GE Healthcare Bio-Sci. Corp., Piscataway, NJ, U.S.A.). After blocking nonspecific binding sites with an Advance blocking agent (GE Healthcare Bio-Sci. Corp.), the membranes were incubated with a goat anti-Ku70 polyclonal antibody (C-19; Santa Cruz Biotechnology, Santa Cruz, CA, U.S.A.), a mouse anti- $\gamma \mathrm{H} 2 \mathrm{AX}$ monoclonal antibody (JBW301) (Upstate Biotechnology Inc., Charlottesville, VA, U.S.A.), a rabbit anti-cleaved caspase-3 (Asp175) polyclonal antibody (9661; Cell Signaling Technology Inc., Danvers, MA, U.S.A.), a rabbit anti-cleaved caspase-7 (Asp198) polyclonal antibody (9491; Cell Signaling Technology Inc.), a rabbit anti-cleaved PARP (Asp214) polyclonal antibody (9544; Cell Signaling Technology Inc.) or a mouse anti- $\beta$-actin monoclonal antibody (Sigma, St. Louis, MO, U.S.A.). The binding to corresponding proteins was visualized using an Advance Western blotting detection system (GE Healthcare Bio-Sci. Corp.), in accordance with the manufacturer's instructions.

Fluorescence microscopy: The fluorescence in cells was visualized as previously described $[8,11]$. Briefly, the cells were fixed in PBS containing 4\% paraformaldehyde. The fixed cells were first blocked using a blocking solution and then incubated for $30 \mathrm{~min}$ at room temperature with a mouse anti- $\gamma$-H2AX monoclonal antibody (JBW301). After washing with PBS, antibody binding was detected using Alexa fluor 488-conjugated secondary antibodies (Molecular Probes, OR, U.S.A.). The cells were examined under an Olympus IX 70 fluorescence microscope (Olympus, Tokyo, Japan). Images were acquired using an FV300 confocal laser scanning microscope (Olympus).

DAPI staining: DNA was stained with $0.025 \mu \mathrm{g} / \mathrm{m} l$ 4,6-diamino-2-phenylindole (DAPI) fluorescent dye (Boehringer Mannheim, Mannheim, Germany). The distribution of fluorescence signals was monitored using an FV300 confocal laser scanning microscope (Olympus) as previously described $[8,16]$.

Clonogenic survival assay: Clonogenic survival assay was performed as previously described [12].

Statistical analysis: Results were expressed as mean \pm standard deviation (SD) $(n=3)$, and statistical analysis was performed by ANOVA followed by the Ryan's multiple comparison tests (ANOVA4). A $P$-value of less than 0.05 indicated statistical significance.

\section{RESULTS}

Previously, our findings revealed that Ku70 -/- MLE cells are markedly sensitive to X-irradiation at low doses, from 0.125 to 2 Gy as compared with $\mathrm{Ku} 70$ +/- MEL cells (control cells) [12], suggesting that $\mathrm{Ku} 70$ plays a key role in radioresistance at doses lower than 2 Gy in lung epithelial cells. However, it remains unclarified whether Ku70 plays a role in radioresistance at doses higher than 2 Gy and works as an inhibitor of radiation-induced death of lung epithelial cells. To clarify whether Ku70 plays a role in radioresistance at doses higher than 2 Gy in lung epithelial cells, we examined the radiosensitivity of $\mathrm{Ku} 70-/-$ MLE cells and Ku70 $+/-$ MLE cells 6 days after irradiation by clonogenic assay. First, we confirmed the expression of $\mathrm{Ku} 70$. Consistent with our previous study [12], Western blot analysis showed that $\mathrm{Ku} 70$ was expressed in control $(\mathrm{Ku} 70+/-)$ MLE cells, but not in Ku70 -/- MLE cells (Fig. 1A). Expectedly, $\beta$-actin was expressed in both cell lines. As shown in Fig. 1B, Ku70 -/- MLE cells were markedly sensitive to X-irradiation at doses 2 and 4 Gy as compared with Ku70 +/- MLE cells $(P<0.05)$. These findings suggest that Ku70 plays a key role in radioresistance, at least, at doses 2 and 4 Gy in lung epithelial cells.

Figure 2 shows representative morphological changes of $\mathrm{Ku} 70$-/- MLE cells following exposure to X-rays (2 or 4 Gy). After X-irradiation, a portion of Ku70 -/- cells exhibited the characteristic features of apoptosis, namely, nuclear condensation and fragmentation, in a dose-dependent manner. On the other hand, the mitotic phase was observed in the control $\mathrm{Ku} 70+/-$ MLE cells with or without X-irradiation, whereas it was observed in only Ku70 -/- MLE cells without $\mathrm{X}$-irradiation, but not in those with $\mathrm{X}$-irradiation. As shown in Fig. 3A, we also observed that $\mathrm{X}$-irradiation of $\mathrm{Ku} 70$-/- MLE cells resulted in a low cell number, owing to the appearance of detached cells at $48 \mathrm{hr}$, as shown by light microscopy. Next, we examined by Western blot analysis whether X-irradiation induces caspase-dependent apoptosis of $\mathrm{Ku} 70-/-$ MLE cells. As shown in Fig. 3B, we found that the active forms of all caspases examined are highly expressed in the Ku70 -/- MLE cells after X-irradiation. Furthermore, the processed form of poly (ADP-ribose) polymerase (PARP), which is among the characteristic substrates of caspase- 3 and caspase-7 activated during apoptosis was expressed at higher levels in $\mathrm{Ku} 70-/-$ MLE cells than in control cells after X-irradiation. These findings indicated that X-irradiation mainly induces apoptosis associated with the activation of caspase- 3 and caspase- 7 in $\mathrm{Ku} 70-/-$ MLE cells compared with control cells. 


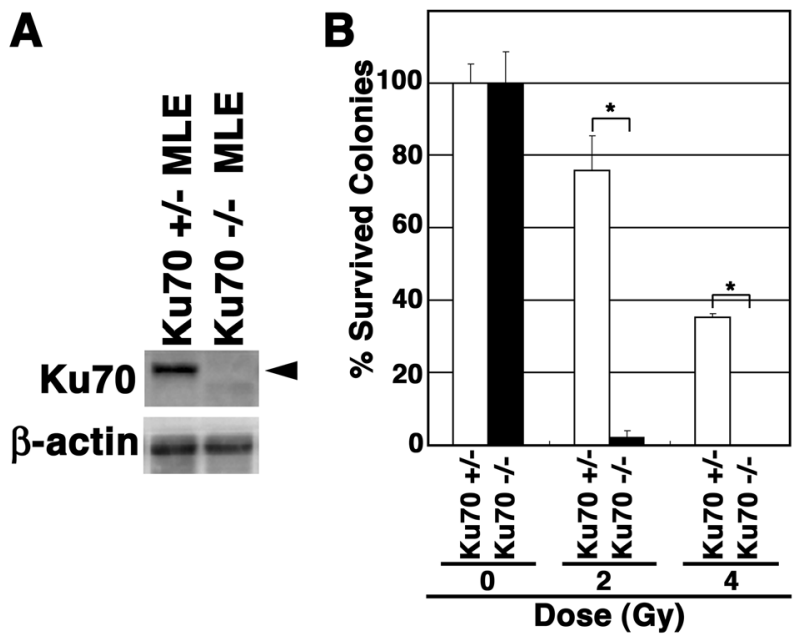

Fig. 1. Hypersensitivity to X-irradiation (2 and 4 Gy) of Ku70 $-/-$ murine lung epithelial (MLE) cells. (A) Expression of Ku70 in $\mathrm{Ku} 70-/-$ and control (Ku70 +/-) MLE cells. Total cell lysates from each cell line were analyzed by Western blotting using an anti-Ku70 antibody or an anti- $\beta$-actin antibody. An arrowhead indicates a Ku70-specific band. (B) Clonogenic survival assay. Cells were seeded at a density of 200 cells per dish in $60-\mathrm{mm}$ dishes. $\mathrm{Ku} 70-/-$ and control (Ku70 +/-) MLE cells were exposed to Xirradiation at a dose of 2 or 4 Gy and were further incubated for 6 days postirradiation. The cells were subsequently stained, fixed with $2 \%$ methylene blue containing $50 \%$ methanol and visualized under an Olympus CKX41 microscope. Colonies containing more than 50 cells were scored as survivors. The colonies were counted, and survival rate was calculated by dividing the number of colonies of treated cells by that of the non-treated control. All exposures were carried out in triplicate and were repeated more than three times. Error bars denote $\mathrm{SD}(\mathrm{n}=3)$. Significant difference was observed in irradiated cells between $\mathrm{Ku} 70-/-$ and $\mathrm{Ku} 70+/-$ MLE cells. The asterisk indicates $P<0.05$.
DSB is the most critical DNA damage [5]. One DNA DSB is sufficient to kill a cell, when it is not repaired. $\gamma \mathrm{H} 2 \mathrm{AX}$ is a sensitive indicator of DSB induced by $\mathrm{X}$-irradiation as well as drugs, e.g., bleomycin and etoposide [16, 24]. To clarify the roles of $\mathrm{Ku} 70$ in $\gamma \mathrm{H} 2 \mathrm{AX}$ elimination after X-irradiation in vivo, we examined X-irradiation-induced H2AX phosphorylation and $\gamma \mathrm{H} 2 \mathrm{AX}$ elimination in extracts from $\mathrm{Ku} 70$ -/- MLE cells and control cells by Western blot analysis and confocal laser scanning microscopy using the anti- $\gamma \mathrm{H} 2 \mathrm{AX}$ antibody (Fig. 4). Following X-irradiation, a high level of $\gamma \mathrm{H} 2 \mathrm{AX}$ was detected in extracts from both cell lines at 1 hr postirradiation (Fig. 4A). Although $\gamma \mathrm{H} 2 \mathrm{AX}$ elimination from 1 to $8 \mathrm{hr}$ after $\mathrm{X}$-irradiation was detected in both cell lines, the elimination from Ku70 -/- MLE cells was slower than that from the control cells (Fig. 4A and 4B, data not shown). These findings suggest the persistence of unrepaired DSBs in $\mathrm{Ku} 70-/-$ MLE cells.

\section{DISCUSSION}

In this study, we found that Ku70 plays a key role in radioresistance at doses 2 and 4 Gy in lung epithelial cells. We also found that the X-irradiation-induced cell death was caused by caspase-dependent apoptosis of Ku70 -/- MLE cells. Furthermore, our findings suggest that the increased sensitivity to X-irradiation-induced apoptosis caused by $\mathrm{Ku} 70$ deficiency is associated with the accumulation of DSBs in MLE cells.

A form of programmed cell death, which is mainly activated by irradiation of cancer cells, contributes significantly to the antineoplastic effect of radiation therapy. A full understanding of the multifaceted relationship between apoptosis and autophagy will be critical for the assessment of anticancer strategies [2]. Recently, it was reported that knockdown of DNA-PKcs radiosensitizes glioblastoma by inducing

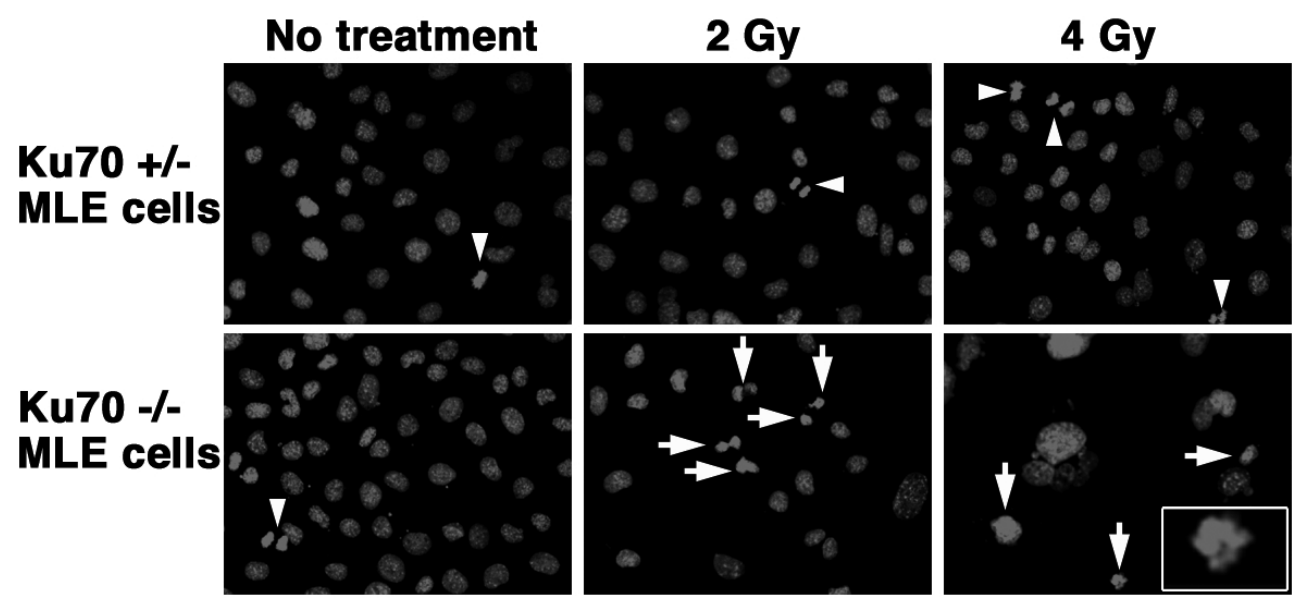

Fig. 2. Apoptotic morphology of Ku70 MLE -/- cells 2 days after X-irradiation. The morphological changes of $\mathrm{Ku} 70-/-$ and $\mathrm{Ku} 70+/-$ MLE cells were examined by fluorescence microscopy after X-irradiation (2 or 4 Gy). The cells were fixed and stained with DAPI. Typical cells, which show nuclear condensation or fragmentation, are indicated by arrows. Typical mitotic-phase cells are indicated by arrowheads. White panel: An enlarged image of the typical cell, which shows nuclear condensation. 

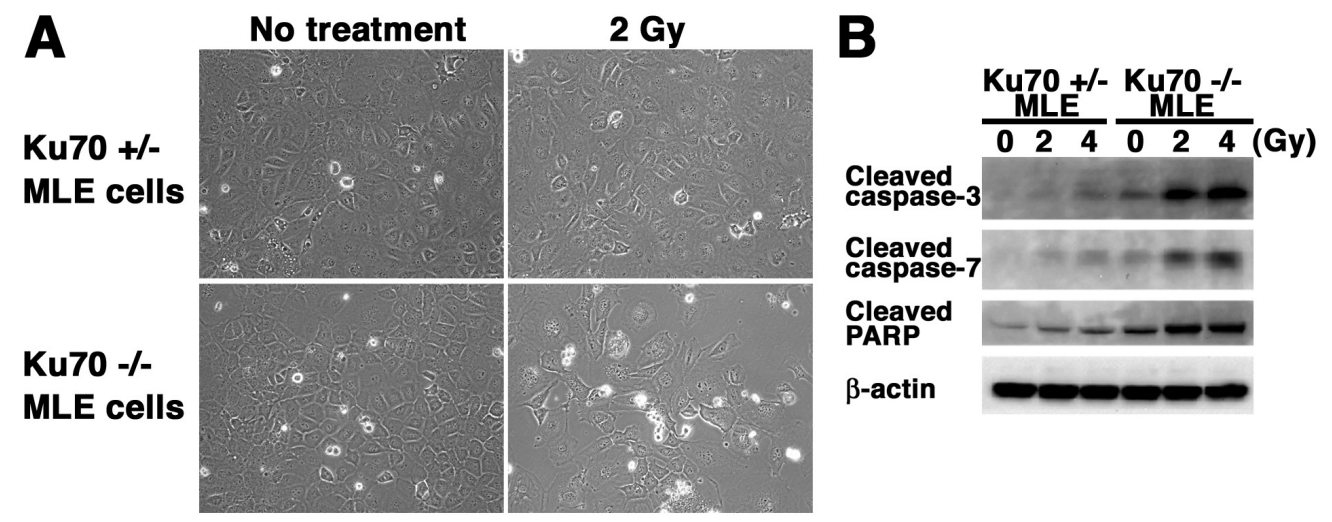

Fig. 3. Morphological and biochemical features of apoptosis in Ku70 -/- MLE cells $48 \mathrm{hr}$ after X-irradiation. (A) Phase-contrast images of Ku70 -/- and Ku70 +/- MLE cells 48 hr after X-irradiation. (B) Western blot analysis of apoptosis-related proteins in Ku70 -/- MLE cells $48 \mathrm{hr}$ after X-irradiation. Expressions of cleaved PARP, cleaved caspase- 3 and cleaved caspase- 7 were evaluated in Ku70 - /- and Ku70 +/- MLE cells with or without X-irradiation ( 2 or $4 \mathrm{~Gy}$ ) by Western blot analysis. $\beta$-actin was used as the loading control. Results shown are from a representative experiment from a total of three performed.
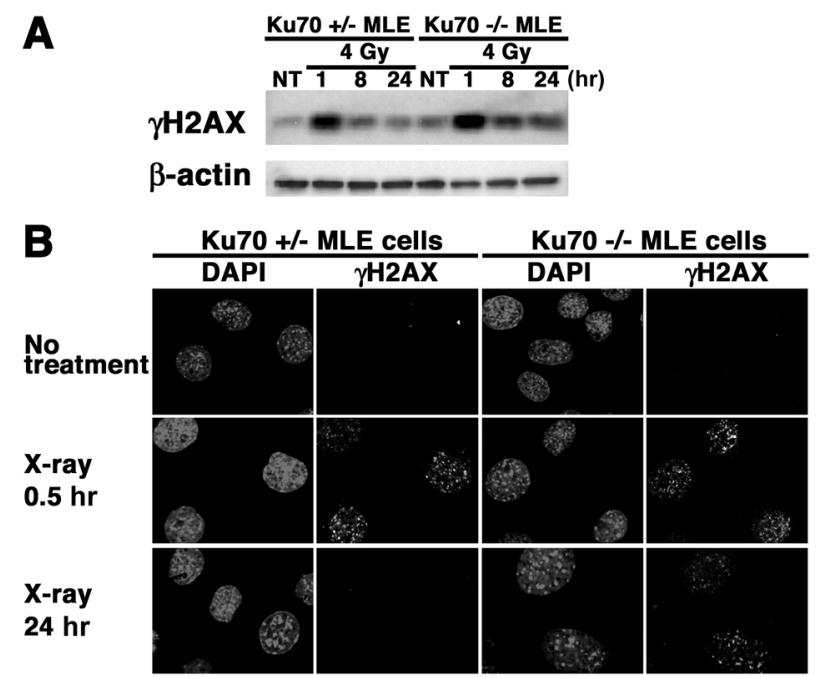

Fig. 4. Persistence of $\gamma \mathrm{H} 2 \mathrm{AX}$ in $\mathrm{Ku} 70-/-$ MLE cells compared with $\mathrm{Ku} 70+/-$ MLE cells. (A) Western blot analysis of $\gamma \mathrm{H} 2 \mathrm{AX}$ expression and $\gamma \mathrm{H} 2 \mathrm{AX}$ elimination in $\mathrm{Ku} 70-/-$ MLE cells after $\mathrm{X}$-irradiation. The Ku70 -/- and Ku70 +/- MLE cells were either nonirradiated or irradiated with 4 Gy X-rays. Each of the total protein samples from the cells was prepared 1,8 or $24 \mathrm{hr}$ after $\mathrm{X}$-irradiation. $\gamma \mathrm{H} 2 \mathrm{AX}$ protein level was determined by Western blot analysis using specific antibodies against $\gamma \mathrm{H} 2 \mathrm{AX}$. $\beta$-actin was used as the loading control. Results shown are from a representative experiment from a total of two performed. NT: No treatment. (B) Immunofluorescences of $\gamma \mathrm{H} 2 \mathrm{AX}$ after X-irradiation. The cells were irradiated with 2 Gy and immunofluorescence-labeled for $\gamma \mathrm{H} 2 \mathrm{AX}$ at the indicated times. Nuclear DNA was counterstained with DAPI.

autophagy [29]. $\mathrm{Ku}$, which is a heterodimer of $\mathrm{Ku} 70$ and $\mathrm{Ku} 80$, is essential for the accumulation of DNA-PKcs at DSBs in the early stage following irradiation [20]. The activity of DNA-PKes is Ku-dependent and required for NHEJ.
Most recently, it has been reported that apoptosis is not the major type of cell death induced by X-irradiation, although $\mathrm{X}$-irradiation activates the cell death pathway such as apoptosis and autophagy [18]. On the other hand, previously, we showed that Ku80 served, at least in part, as the antiapoptotic factor that inhibits caspase-3-dependent apoptosis triggered by $\mathrm{X}$-irradiation-induced DNA damage in Ku80-deficient xrs-6 cells established from Chinese hamster ovary (CHOK1) cells [7]. In this study, Ku70 -/- MLE cells showed a high sensitivity to X-irradiation as shown by the detection of dose-dependent caspase- 3 and caspase- 7 activations, and cleavage of PARP. PARP is a substrate of caspase- 3 and caspase-7. Therefore, X-irradiation-induced apoptosis might be dependent on the effector caspase (i.e., caspase- 3 and caspase-7) in $\mathrm{Ku} 70-/-$ MLE cells, although further studies are needed to clarify the mechanism in detail.

Histone H2AX is rapidly phosphorylated at serine 139 in response to DNA DSBs [23]. On the other hand, it was reported that the elimination of $\gamma \mathrm{H} 2 \mathrm{AX}$ reflects DSB repair [24]. In many cultivated cell lines, the rate of $\gamma \mathrm{H} 2 \mathrm{AX}$ elimination correlates with the rate of DSB rejoining and, therefore, can serve as a marker of repair of X-irradiationinduced DSBs in normal cultivated cells and in normal mammalian tissues [26]. The phosphorylation of H2AX and the elimination of $\gamma \mathrm{H} 2 \mathrm{AX}$ at X-irradiation-induced DSBs proceed in a tissue-specific manner in vivo $[1,14,15,26]$. In this study, we examined the phosphorylation of H2AX and elimination of $\gamma \mathrm{H} 2 \mathrm{AX}$ in $\mathrm{Ku} 70$-deficient lung cells and control cells by Western blot analysis after X-irradiation. Our findings showed the persistence of unrepaired DSBs in Ku70 -/- MLE cells compared with Ku70 +/- MLE cells. This observation suggests that the elimination of $\gamma \mathrm{H} 2 \mathrm{AX}$ from the MLE cells observed in this study, at least in part, proceeded in a $\mathrm{Ku} 70$-dependent DSB repair pathway.

There are two pathways, i.e., NHEJ and homologous recombination (HR), for DSB repair in mammalian cells [20]. The control mechanisms underlying the subcellular local- 
ization of $\mathrm{Ku} 70$ and $\mathrm{Ku} 80$ play a key role in regulating the physiological function of not only $\mathrm{Ku}$ itself, but also other NHEJ core factors $[6,11,17,20]$. Recently, using Ku70 -/MLE cells, we have shown that $\mathrm{Ku} 70$ is essential for the accumulations of XRCC4 and XLF, but not those of Artemis and $\mathrm{p} 21$, at DSBs in the early stage following irradiation of lung epithelial cells $[10,11]$. Thus, the accumulation of the NHEJ core factors XRCC4 and XLF is dependent on $\mathrm{Ku}$; however, that of another NHEJ factor, Artemis, which plays a role in both the NHEJ and HR pathways, is independent of $\mathrm{Ku}$ in MLE cells. Altogether, we consider that the persistence of unrepaired DSBs after X-irradiation might be caused by a deficiency of the Ku70-dependent NHEJ process in $\mathrm{Ku} 70$ $-/-$ MLE cells.

It is important to elucidate the molecular mechanisms underlying the radioresistance and chemoresistance of lung cancer and normal cells, because human lung cancer causes many deaths worldwide. Recently, a significant association between the polymorphisms of genes in the NHEJ pathway and lung cancer susceptibility and prognosis has been reported [27]. Therefore, it is important to analyze the role of $\mathrm{Ku} 70$ in lung cancer susceptibility and prognosis, as well as the role of $\mathrm{Ku} 70$ in the molecular mechanism underlying cellular resistance to chemotherapy and radiotherapy. Further studies are required to elucidate the radioresistance and chemoresistance underlying the Ku70-dependent antiapoptotic mechanisms of the lung epithelial cell lines, which may lead to a better understanding of not only the molecular mechanisms underlying Ku70 function in lung epithelial cells, but also the development of new radiosensitizers that target Ku70 or other NHEJ factors.

ACKNOWLEDGMENTS. This work was supported in part by grants from the Ministry of Education, Culture, Sports, Science and Technology, Japan. We also thank Mr. S. Ikenaga for technical assistance with the immunoblotting.

\section{REFERENCES}

1. Dickey, J. S., Redon, C. E., Nakamura, A. J., Baird, B. J., Sedelnikova, O. A. and Bonner, W. M. 2009. H2AX: functional roles and potential applications. Chromosoma 118: 683-692. [Medline] [CrossRef]

2. Eisenberg-Lerner, A., Bialik, S., Simon, H. U. and Kimchi, A. 2009. Life and death partners: apoptosis, autophagy and the cross-talk between them. Cell Death Differ. 16: 966-975. [Medline] [CrossRef]

3. Gu, Y., Jin, S., Gao, Y., Weaver, D. T. and Alt, F. W. 1997. Ku70deficient embryonic stem cells have increased ionizing radiosensitivity, defective DNA end-binding activity, and inability to support V(D)J recombination. Proc. Natl. Acad. Sci. U.S.A. 94: 8076-8081. [Medline] [CrossRef]

4. Hopfner, K. P., Putnam, C. D. and Tainer, J. A. 2002. DNA double-strand break repair from head to tail. Curr. Opin. Struct. Biol. 12: 115-122. [Medline] [CrossRef]

5. Khanna, K. K. and Jackson, S. P. 2001. DNA double-strand breaks: signaling, repair and the cancer connection. Nat. Genet. 27: 247-254. [Medline] [CrossRef]

6. Koike, M. 2002. Dimerization, translocation and localization of Ku70 and Ku80 proteins. J. Radiat. Res. (Tokyo) 43: 223-236.
[Medline] [CrossRef]

7. Koike, M. and Koike, A. 2004. Establishment and characterization of stable cell lines expressing human Ku80 tagged with enhanced green fluorescent protein. J. Radiat. Res. (Tokyo) 45: 119-125. [Medline] [CrossRef]

8. Koike, M. and Koike, A. 2008. Accumulation of Ku80 proteins at DNA double-strand breaks in living cells. Exp. Cell Res. 314: 1061-1070. [Medline] [CrossRef]

9. Koike, M., Shiomi, T. and Koike, A. 2001. Dimerization and nuclear localization of Ku proteins. J. Biol. Chem. 276: 1116711173. [Medline] [CrossRef]

10. Koike, M., Yutoku, Y. and Koike, A. 2011. Accumulation of p21 proteins at DNA damage sites independent of p53 and core NHEJ factors following irradiation. Biochem. Biophys. Res. Commun. 412: 39-43. [Medline] [CrossRef]

11. Koike, M., Yutoku, Y. and Koike, A. 2011. Accumulation of $\mathrm{Ku} 70$ at DNA double-strand breaks in living epithelial cells. Exp. Cell Res. 317: 2429-2437. [Medline] [CrossRef]

12. Koike, M., Yutoku, Y. and Koike, A. 2011. Establishment of Ku70-deficient lung epithelial cell lines and their hypersensitivity to low-dose X-irradiation. J. Vet. Med. Sci. 73: 549-554. [Medline] [CrossRef]

13. Koike, M., Ikuta, T., Miyasaka, T. and Shiomi, T. 1999. Ku80 can translocate to the nucleus independent of the translocation of Ku70 using its own nuclear localization signal. Oncogene 18: 7495-7505. [Medline] [CrossRef]

14. Koike, M., Mashino, M., Sugasawa, J. and Koike, A. 2008. Histone H2AX phosphorylation independent of ATM after Xirradiation in mouse liver and kidney in situ. J. Radiat. Res. (Tokyo) 49: 445-449. [Medline] [CrossRef]

15. Koike, M., Sugasawa, J., Yasuda, M. and Koike, A. 2008. Tissue-specific DNA-PK-dependent H2AX phosphorylation and $\gamma-\mathrm{H} 2 \mathrm{AX}$ elimination after X-irradiation in vivo. Biochem. Biophys. Res. Commun. 376: 52-55. [Medline] [CrossRef]

16. Koike, M., Koike, A., Sugasawa, J., Toyooka, T. and Ibuki, Y. 2010. Dynamics of Ku80 in living hamster cells with DNA double-strand breaks induced by chemotherapeutic drugs. J. Vet. Med. Sci. 72: 1405-1412. [Medline] [CrossRef]

17. Koike, M., Awaji, T., Kataoka, M., Tsujimoto, G., Kartasova, T., Koike, A. and Shiomi, T. 1999. Differential subcellular localization of DNA-dependent protein kinase components $\mathrm{Ku}$ and DNA-PKcs during mitosis. J. Cell Sci. 112: 4031-4039. [Medline]

18. Kuwahara, Y., Oikawa, T., Ochiai, Y., Roudkenar, M. H., Fukumoto, M., Shimura, T., Ohtake, Y., Ohkubo, Y., Mori, S., Uchiyama, Y. and Fukumoto, M. 2011. Enhancement of autophagy is a potential modality for tumors refractory to radiotherapy. Cell Death Dis. 2: e177 [Medline] [CrossRef].

19. Lee, M. N., Tseng, R. C., Hsu, H. S., Chen, J. Y., Tzao, C., Ho, W. L. and Wang, Y. C. 2007. Epigenetic inactivation of the chromosomal stability control genes BRCA1, BRCA2, and XRCC5 in non-small cell lung cancer. Clin. Cancer Res. 13: 832-838. [Medline] [CrossRef]

20. Mahaney, B. L., Meek, K. and Lees-Miller, S. P. 2009. Repair of ionizing radiation-induced DNA double-strand breaks by nonhomologous end-joining. Biochem. J. 417: 639-650. [Medline] [CrossRef]

21. Omori, S., Takiguchi, Y., Suda, A., Sugimoto, T., Miyazawa, H., Takiguchi, Y., Tanabe, N., Tatsumi, K., Kimura, H., Pardington, P. E., Chen, F., Chen, D. J. and Kuriyama, T. 2002. Suppression of a DNA double-strand break repair gene, Ku70, increases radio- and chemosensitivity in a human lung carcinoma cell line. DNA Repair (Amst.) 1: 299-310. [Medline] [CrossRef] 
22. Ouyang, H., Nussenzweig, A., Kurimasa, A., Soares, V. C., Li, X., Cordon-Cardo, C., Li, W., Cheong, N., Nussenzweig, M., Iliakis, G., Chen, D. J. and Li, G. C. 1997. Ku70 is required for DNA repair but not for $\mathrm{T}$ cell antigen receptor gene recombination in vivo. J. Exp. Med. 186: 921-929. [Medline] [CrossRef]

23. Rogakou, E. P., Pilch, D. R., Orr, A. H., Ivanova, V. S. and Bonner, W. M. 1998. DNA double-stranded breaks induce histone H2AX phosphorylation on serine139. J. Biol. Chem. 273: 5858-5868. [Medline] [CrossRef]

24. Rothkamm, K. and Löbrich, M. 2003. Evidence for a lack of DNA double-strand break repair in human cells exposed to very low x-ray doses. Proc. Natl. Acad. Sci. U.S.A. 100: 5057-5062. [Medline] [CrossRef]

25. Shiloh, Y. 2003. ATM and related protein kinases: safeguarding genome integrity. Nat. Rev. Cancer 3: 155-168. [Medline] [CrossRef]
26. Svetlova, M. P., Solovjeva, L. V. and Tomilin, N. V. 2010. Mechanism of elimination of phosphorylated histone H2AX from chromatin after repair of DNA double-strand breaks. Mutat. Res. 685: 54-60. [Medline] [CrossRef]

27. Tseng, R. C., Hsieh, F. J., Shih, C. M., Hsu, H. S., Chen, C. Y. and Wang, Y. C. 2009. Lung cancer susceptibility and prognosis associated with polymorphisms in the nonhomologous endjoining pathway genes: a multiple genotype-phenotype study. Cancer 115: 2939-2948. [Medline] [CrossRef]

28. Watters, G. P., Smart, D. J., Harvey, J. S. and Austin, C. A. 2009. H2AX phosphorylation as a genotoxicity endpoint. Mutat. Res. 679: 50-58. [Medline] [CrossRef]

29. Zhuang, W., Li, B., Long, L., Chen, L., Huang, Q. and Liang, Z. Q. 2011. Knockdown of the DNA-dependent protein kinase catalytic subunit radiosensitizes glioma-initiating cells by inducing autophagy. Brain Res. 1371: 7-15. [Medline] [CrossRef] 